\title{
A Review of Curriculum Change and Innovation for Higher Education
}

\author{
Mei Yuan Law \\ Correspondence: Mei Yuan Law, Cluster of Education and Social Sciences, Open University Malaysia, Kuala Lumpur, \\ Malaysia.
}

Received: December 3, 2021

Accepted: January 12, 2022

Online Published: January 13, 2022

doi:10.11114/jets.v10i2.5448

URL: https://doi.org/10.11114/jets.v10i2.5448

\begin{abstract}
The effective curriculum has become a critical component of higher education because of the shifts in the techno-socio-economic landscape and digital revolutions in industry 4.0. In this paper, a review of existing works related to curriculum change and innovation for higher education institutions provides insight into the topic. The paper is divided into several sections of the review. A general understanding and introduction of the context of Curriculum 4.0 in higher education are elaborated in this review. The relative theories that underpin curriculum change and innovation in educational institutions are presented. The paper also discusses and reviews the processes and procedures involved in managing curriculum change and innovation. The issues related to embracing and managing curriculum change and innovation are also highlighted and discussed in this paper.
\end{abstract}

Keywords: theories for curriculum change and innovation, higher education, theories, curriculum change and innovation in higher education

\section{Introduction}

An effective curriculum is one of the critical components of educations besides infrastructure and technology, policies and procedures, and leadership. Smooth teaching and learning processes depend on efficient and practical guidelines that guide the transmission of knowledge from educators to learners. A curriculum entails all experiences learners gain through workshops, classrooms, playgrounds, and interaction with educators (Blackmore \& Kandiko, 2012). Consequently, a curriculum encompasses all aspects of a student's life, necessitating the need for educational stakeholders to devise a curriculum that enriches learners' social, political, and economic well-being. A sound curriculum should exhaustively align learners with the prevailing market needs on a global scale (Kandiko Howson \& Kingsbury, 2021). Therefore, teachers and other stakeholders should adhere to a curriculum issued by the government to ensure that learners get helpful knowledge and skills of the twenty-first century.

The economic, social, and political aspects change over time, revealing that a curriculum is likely to become less effective after a period of adoption. The tremendous advancement in science and technology leads to new knowledge and skills, necessitating timely revision of existing curriculums to avoid instances where learners gain obsolete skills that lack global competitiveness. Curriculum change is a learning process for learners and teachers as they endeavour to gain new knowledge about the market and societies (Blackmore \& Kandiko, 2012). A critical understanding of a curriculum change is vital in ensuring that all stakeholders understand their roles in achieving set goals (Alsubaie, 2016). The planners also need to understand the ability of the economy to support the desired changes to avoid instances where a good curriculum faces implementation challenges. Given the ever-changing technological environment, teachers and students will be forced to utilize diverse learning materials, which may be costly, hindering effective transition. However, with sound implementation strategies, curriculum change plays a crucial role in fostering healthy learning and facilitating global competitiveness.

Curriculum 4.0 aims at ensuring that learners are equipped with skills and knowledge aligned with the needs of the twenty-first century. Learning institutions globally are faced with challenges resulting from the tectonic shifts in the techno-socio-economic landscape and digital revolutions taking place in industry 4.0. As a result, nations desire to shift from an industrial to a knowledge approach to benefit from the continuing technological developments. Curriculum 4.0 will facilitate the process of discovery through experimentation and exploration, unlike the previous system, which utilized a one size fits all approach. Learners will have an opportunity to customize learning pathways depending on pace, style, and learning orientation. Consequently, learners will combine a liberal mindset covering a wide range of knowledge across disciplines with in-depth skills in a specialized area. The move will be vital in ensuring that learners 
can get absorbed in a wide range of industries and create employment opportunities based on acquired knowledge and skills (Global Focus, 2021). Therefore, Curriculum 4.0 desires to ensure that learners engage in multiple productive activities leading to personal and national growth.

The critical goals of Curriculum 4.0 include holistic development, technology integration, social responsibility, management of self, dealing with uncertainty, innovation and creativity, pedagogy, and practice orientation. Learners will be exposed to a wide range of knowledge such as art and design, humanities, languages, sciences, and natural studies. The exposure will ensure that graduates can fit in several fields, reducing unemployment. Given the rising adoption of big data and artificial intelligence among corporations, learning institutions will also be forced to incorporate technology and innovation across all disciplines. Consequently, learners will be aware of technological changes affecting their area of specialization leading to improved research and heightened global competitiveness (Blackmore \& Kandiko, 2012). Moreover, learners will learn self-development strategies that are vital during learning and in working environments. Therefore, it is vital to learn the literature behind curriculum change to establish the importance of adopting Curriculum 4.0. A critical understanding of the procedures and processes involved in managing curriculum change and innovation is crucial in aiding policymakers to understand individual and collective obligations (Global Focus, 2021). Finally, analyzing issues of concern in managing and embracing curriculum change and innovations will necessitate an alternative course of action among key stakeholders.

\section{Theories that Underpin Curriculum Change and Innovation in Educational Institutions}

\subsection{Complexity Theory}

Complexity theory advocates change, adaptation, and evolution in the interests of survival through a combination of competition and survival. The theory postulates a defined relationship between an organism and the environment where a change in one positively or negatively affects the other. Consequently, individuals cannot consider the environment without getting concerned about the other. A system must be seen as a whole containing several parts which must be considered while making critical decisions. The system is also multifaceted, dynamic, thereby producing new realities, collectivities, and relations. Given that both individuals and systems change from time to time, there is a need to develop new realities that foster the system's well-being as a whole (Kolmos, Hadgraft \& Holgaard, 2015). Consequently, the curriculum has to change from time to time to accommodate the needs of social, political, and economic systems. In so doing, individuals get aligned with the prevailing institutional needs leading to high productivity and efficiency.

Like other complex systems, education investigates the external environments and resolves the necessary internal developments and adjustments to survive in the changing holistic frameworks. The change process can be self-organized where stakeholders explore the possible changes in the external environment and implement changes that will lead to the long-term growth and development of the affected parties. For instance, the twenty-first century has been characterized by the tremendous use of technology in learning (Fenwick \& Dahlgren, 2015). Consequently, educational stakeholders must adopt a curriculum that meets the learning needs of the century. Because of automation, the job market has also significantly changed, and learners must be well equipped with prevailing and future market needs. When education stakeholders learn that the learning and job markets are greatly affected by technology, they initiate a self-reorganization process to fit in the external environment.

Moreover, in the self-organization process, both the organism and the environment have a unique characteristic in that they self-create based on the prevailing circumstances. The concept of uniqueness postulates that a notable change in one necessitates another change. Failure of one party to change creates a niche that must be filled through a well-thought process (Blackmore \& Kandiko, 2012). Competition among various systems to fill the gap leads to a collective change in multiple internal systems. For instance, technology has resulted in changes in the healthcare sector, where big data is used to diagnose and treat diseases (Deogratias, 2018). Given that nurses and other healthcare providers must be conscious of the present and future changes, there is a need for educational sectors to adopt a curriculum that meets the needs of other sectors. In other words, when the external environment changes, it creates a massive gap that must be filled collectively. Multiple internal players must unite in embracing positive changes while negative impacts are mitigated to enhance continuity. Consequently, both the organism and the environment are unique and can procreate. Whenever one changes, the other must strategize on filling the gap left by the transformation.

The complexity theory also postulates that connectedness requires a distributed knowledge system as it is not located in a command centre such as a government department. Instead, knowledge circulates throughout a system, and communication and coordination are instrumental in causing a positive change. For instance, curriculum 4.0 desires to facilitate cultural transmissions, environmental adaptations, and exhaustive personality development. The goals have a serial and non-serial relationship, necessitating the unity of multiple stakeholders in formulating an exhaustive and detailed curriculum. Given that knowledge is distributed, the unity of several systems ensures that the curriculum will 
serve the present and future needs of the industry. Educators will be the leading implementers of the changes and must be consulted on the model's applicability in fostering social, political, and economic progress. Government is the key financier of the program and must be involved in the change process to assess its applicability and economic value. Similarly, other key industries such as healthcare, manufacturing, processing, and information technology must be incorporated into the process. In doing so, the diverse systems establish a curriculum that suits the needs of the external environment (Deogratias, 2018). Consequently, there is a need for multiple systems o regularly come together and implement detailed changes that match the changes in the external environment.

Additionally, successfully implementing the complex theory in curriculum changes and innovation requires an interconnectedness of internal systems. The theory is among the curriculum inquires that allows teachers and learners to achieve international educational goals. Teachers and learners should foster a positive learning process where all ideas are respected and advanced to achieve the current and future educational needs. One of the key goals of education 4.0 is to foster a solution-oriented system through practical problem-solving skills. Consequently, there is a need to use a theory that advocates for shared knowledge. Most industries have been faced with numerous challenges amid tremendous technological development. The solution to the issues requires a well-defined strategy that ensures that all stakeholders mitigate the challenges. Individuals also need problem-solving skills at a personal level to enhance individual survivability (Fenwick \& Dahlgren, 2015). For instance, nations have been unable to effectively resolve the issue of unemployment as technology continues to render millions jobless. With the right problem-solving skills and impactful training, graduates can be in a position to create jobs for others without overreliance on the government to create jobs. Consequently, the theory is vital in advocating for interconnectedness in achieving individual and national goals.

The complex theory also advocates for feedback sensitivity, where the interconnectedness of systems paves the way for the achievement of desired results. Various systems interact to produce graduates who fit in the education sector's social, political, and economic realms. Curriculum changes should facilitate a smooth feedback process among the systems to ensure wholesome and high-quality education (Hiver \& Dörnyei, 2015). For instance, the intensified use of technology has led to the heightened use of social media marketing because of increased digital interactions. Unlike in the past, where corporations use traditional marketing platforms such as TV, there is a need to train individuals on digital marketing, which is the prevailing promotion methodology. The approach leads to globalization and the prosperity of corporations and nations. Consequently, the social media platforms can be said to provide positive feedback for corporations who change their marketing approach to suit the needs of the potential and existing clients. Learning institutions would also be compelled to focus on the prevailing market needs to create a balanced system (Kershner \& McQuillan, 2016). Therefore, complexity theory in education ensures that systems develop through positive feedback.

Finally, the complexity theory in education paves the way for strategic planning, leading to achieving the desired results. The theory defines the interconnectedness of systems that must work as a whole to attain short-term and long-term needs. The adoption of an effective curriculum requires complex planning to ensure that it meets the needs of the current and future generations. Implementing a curriculum is time-consuming and costly, necessitating an exhaustive and impactful framework. Complexity is a driver of innovations, and educational sectors must benefit from the developments. Planning ensures that all players know the market needs and the strategies for achieving the desired needs (Kolmos et al., 2015). For instance, Curriculum 4.0 advocates for heightened exploration and experimentation, which necessitates the need for key stakeholders to plan on how to achieve the goal. Through interconnection and planning, the involved parties can plan on the implementation process and align individuals with the industrial needs.

\subsection{Critical Theory}

The critical theory addresses schooling, economy, society, culture, education, and governance. The philosophy is concerned with being critical of the prevailing social view by paying attention to the beliefs that only cater to the needs of the privileged and changing that. Technological development in the twenty-first century has changed how individuals socialize, transact, and work because of the heightened use of machines and electronic gadgets such as mobile phones and personal computers. The education system has also significantly changed where individuals can easily access learning materials, and educators can teach using e-learning platforms. Individuals without a profound knowledge of the technical requirements find it hard to learn and get absorbed in the job market. Consequently, individuals need to gain the required knowledge and education to remain relevant in the industry. Although the critical theory postulates that people should gear towards causing change individually, the education sector is broad, and the state and federal governments provide the services. As a result, the government is responsible for choosing what is best for the nationals. Curriculum changes open opportunities for all, leading to better societies because of empowerment (Giroux, 2019). Therefore, critical theory is vital for planners and executors of curriculum changes.

Additionally, the critical theory questions how the prevailing systems can better improve education irrespective of socio-economic backgrounds. Globally, children have been deprived of the right to education because of poverty and 
lack of access to learning institutions. One of the key sustainable development goals is providing quality education for all. Nations have been tasked with ensuring that all children get educated to be productive socially, economically, and politically. The requirements of the United Nations align with the critical theory, which postulates that existing systems can better the education of learners without focusing on negative aspects such as social-economic backgrounds and ethnicity. That being the case, governments have to ensure that they align individuals with the prevailing global market needs, given that most corporations operate internationally. Curriculum 4.0 desires to ensure that individuals are innovative and capable of working worldwide without geographical barriers. The application of the critical theory ensures that all stakeholders understand the needs of communities and those of the industries before making vital decisions. The empowerment of the less privileged opens up opportunities for many who become future job creators leading to economic prosperity (Wang \& Torrisi-Steele, 2015). Therefore, critical theory should be a key reference point for stakeholders to make positive changes.

Furthermore, the theory advocates the need for stakeholders to cater to all learners critically in all aspects. Curriculum changes are geared towards ensuring that the needs of the government, learners, and social institutions are met. The development of a curriculum is a complex and involving process that details all the gaps and possible changes. Although nations have embarked on promoting free education for young learners, higher education remains expensive, mainly because of the rising cost of living and unemployment. Governments may implement a curriculum that turns out to be ineffective, leading to wastage of resources and time. As a result, nations need to ensure that all critical learners' needs are well evaluated before implementation (McArthur, 2021). For instance, the rising technology adoption in critical industries and learning institutions necessitates technical resources, which may be unaffordable among several students. Consequently, although a curriculum may be well outlined and geared towards achieving individual and national goals, a lack of resources will lower efficiency. However, by applying critical theory, formulators and implementers analyze all the positives and negatives, leading to better learning (Fleming, 2016). Therefore, the need to critically address educational needs leads to the adoption of a curriculum that is fruitful and at the same time manageable from a social, political, and economic perspective.

Furthermore, a new curriculum should consider formal and informal programs based on a political point of view. The new programs should emphasize how daily study texts create value among students and better interpersonal relationships among stakeholders. An education system is political and aims at creating a society of democratic equality. Consequently, a curriculum change must be viewed as a political process where stakeholders aim at providing quality education for all equally without discrimination. Education should also be pegged on moral ethics to ensure that learners adopt professional skills in line with their areas of specialization. Given that education is viewed as a political process, curriculum changes should discourse and dialogue to ensure that all parties necessary for an effective program get incorporated in significant decision-making. Knowledge is diverse and relative, and nations should constantly assess the existing systems to identify gaps and potential solutions (Fleming, 2016). For instance, Curriculum 4.0 advocates for holistic development using a multidisciplinary orientation approach. Students will be exposed to multiple disciplines across areas and functions to ensure that they can fit in a wide range of specializations amid changing working environments. The exposure will also enable individuals to discover their potential and possible career choices. Therefore, based on the prevailing educational and industrial needs, nations should, from time to time, execute curriculum changes to equip learners with the current and future market needs.

\section{Processes and Procedures Involved in Managing Curriculum Change and Innovation}

Curriculum change entails the introduction of new learning and teaching guidelines revealing that involved stakeholders must establish sound policies and procedures for managing all emergent issues. The following models are vital in ensuring that curriculum change positively benefits all parties involved;

\subsection{Overcoming Resistance to Change (ORC) Model}

The model stipulates that the success of a curriculum depends on the impact a developer makes on other users such as students, teachers, and society as a whole. The change process involves several parties that desire to ensure that the desired results will positively promote individual and social growth. Consequently, developers must ensure that the changes address individuals' misgivings, misapprehensions, and other related factors. The parties involved must be adequately informed of the issues being addressed by the changes, beliefs, values, and assumptions (Mahmood, 2018). The move is vital in ensuring that the implementers understand the goals of the new curriculum and plan for the effective achievement of the desired results. The other issue entails the coordination of implementers to ensure that they do not revolt against the new changes. People within the system should be motivated rather than ordered to avoid instances where they fail to implement ways of achieving the long-term goals of the curriculum. Consequently, developers should identify and deal with employees' concerns in various departments when implementing Curriculum 4.0. The concerns can be categorized into four developmental stages. 


\subsubsection{Unrelated Concerns}

At this stage, teachers do not perceive themselves as having a relationship with the desired curriculum changes. For instance, Curriculum 4.0 desires to focus on the technological empowerment of learners. Consequently, new programs will be introduced to ensure that individuals learn what is expected in the field. At this stage, a teacher may not be aware of such efforts, and if one did, he might not be concerned about the changes (Bank et al., 2017). Consequently, a teacher may not be concerned about the changes since one does not consider influencing the personal and professional; domain.

\subsubsection{Personal Concerns}

At times, teachers may be aware of the desired changes and their impact on their personal and professional well-being. Consequently, they will react to curriculum changes and would be willing to learn how the newly introduced innovations compare with the ones already in use. Curriculum developers should establish procedures that pave the way for teachers to understand their new roles concerning changes.

\subsubsection{Task Related Concerns}

The stage relates to the actual implementation of the desired changes. Teachers are concerned about achieving the newly introduced changes within the stipulated guidelines. The availability of material and teaching strategies are vital issues that all stakeholders must address to avoid situations where teaching and learning procedures do not positively impact the economy. Therefore, curriculum developers should establish procedures that lead to impactful learning throughout the curriculum's lifespan.

\subsubsection{Impact Related Concerns}

At this stage, teachers are concerned about how the innovation will impact other members of society. Teachers must have a framework that prepares learners for job markets and utilize the changes to make individuals more competitive and productive. The implementation process requires developers to constantly address emerging issues related to personal, task-related, and impact-related concerns (Bank, Jippes, Leppink, Scherpbier, den Rooyen, van Luijk \& Scheele, 2017). In the end, all emerging issues can be resolved within the stipulated deadlines without affecting the whole change process.

\subsection{Leadership Obstacle Course (LOC) Model}

Curriculum changes usually face resistance challenges from critical stakeholders such as teachers and learners. The model stipulates that staff resistance is a crucial obstacle to achieving the set goals and proposes collecting data from stakeholders to determine the nature and extent of resistance in implementing a curriculum. The move will be vital in assessing a curriculum's success rate and implementing measures that lead to heightened acceptability (Tran, Hallinger $\&$ Truong, 2017). The assessment of the resistance rate can be carried through the following;

- All members involved in implementing the curriculum must clearly understand the proposed innovation.

- Individuals in the organization must be given the necessary skills to possess capabilities instrumental for carrying out the innovation.

- Additionally, the necessary equipment and materials for the program must be well furnished.

- Where necessary, the developers may modify the existing organizational structure to make it compatible with the suggested innovation.

- The participants must be motivated to spend the required time and effort in making the innovation successful.

Further, the model stipulates that educational changes must be a sequence of three stages;

- Initiation

- Attempted implementation

- Incorporation

The change process is first proposed to the stakeholders who discuss the content of the curriculum. After adoption, the curriculum is implemented and adopted by all learning institutions. With time, individuals get used to the new system leading to higher acceptance levels. The implementation obstacles are tackled at every stage, signalling that the curriculum gains acceptance gradually (Aaron, Ehrhart, Farahnak \& Hurlburt, 2015). Therefore, the model has a feedback and monitoring mechanism in determining whether a solved problem keeps recurring at every stage.

\subsection{Rand Change Agent (RCA) Model}

The model stipulates that organizational dynamics are the barriers to effective curriculum changes. The model also 
advocates for three stages of change: initiation, implementation, and incorporation. The initiation stage entails developers working together to secure support for the anticipated changes. The attainment of full support towards a new program calls for a critical understanding of the legitimacy of the changes. Therefore, curriculum changes require personal support from all involved parties. For instance, teachers may be informed of the desired changes and a guide to effect new programs. The implementation stage entails actualizing the desired changes (Teressa \& Besha, 2020). At this stage, developers introduce new programs and adjust organizational structures to make the changes effective. The incorporation stage entails the proposed changes becoming part of the established guidelines. The success of curriculum implementation is a function of organizational structure, the readiness of local societies, abilities and skills of administrative and academic staff, and the characteristics of the desired change. The implementation phase is also characterized by financial and personnel support to hasten success.

\subsection{Learner-Centered Curriculum Design}

The achievement of high success rates after implementing a curriculum requires a critical understanding of each learner's needs, goals, and interests. The curriculum empowers learners and allows them to shape their learning through choices. Learners should be allowed to choose desired activities and learning experiences. The move to let individuals select areas of interest leads to lower resistance rates making the incorporation process effective. Institutional leaders need to motivate students and teachers to ensure that they support the changes at all times (Mahatma Gandhi National Council of Rural Education, 2020). In the end, individuals will appreciate the changes leading to a successful transition.

\section{Issues of Concern in Embracing and Managing Curriculum Change and Innovation}

\subsection{Teaches Concerns}

Curriculum implementation refers to how educators deliver assessment and instructions using specified resources provided by developers. Curriculum designs provide teachers with lesson plans, scripts, instructional suggestions, and assessment options. The strategies focus on consistency to make it easier for teachers to successfully implement and maintain a circular structure that meets the curriculum objectives (Bell, 2015). Consequently, there is a need for stakeholders involved in causing curriculum changes to critically understand the concerns and beliefs of the teachers who offer insights on whether the desired changes will be met with failure or success. Teachers' beliefs significantly affect instructions necessitating understanding their concerns, values, and perceptions. The developers should prepare teachers for the planned changes through a collaborative process (Cetin, 2016). For instance, professional development can ensure that teachers understand the processes and try the new curriculum in a class to support teacher learning. According to Rakes and Dunn (2015), a collaborative process also plays a vital role in ensuring that developers understand the challenges likely to be faced during the implementation and take necessary corrective measures. Therefore, teachers should be involved in the curriculum preparation process for higher acceptance levels.

Additionally, the curriculum may hinder the successful implementation of desired changes. The failure of developers to fully understand individual and institutional needs during the initiation process can significantly affect the management and embracement of a new curriculum. According to Torres (2016), although most curricula are accurate, they lack pedagogical guidance to help teachers understand lessons fully before teaching them. The failure of curriculum developers to focus on all fields before making critical decisions can significantly affect the success or failure of the changes. Therefore, stakeholders need to provide a comprehensive and detailed curriculum that caters to the needs of all parties involved.

\subsection{Administrative and Professional Support}

Training is among the avenues that result in high implementation success since teachers learn of their duties and roles in causing positive changes that promote the welfare of the learners. However, the organizational structure can lead to lower success levels, given that teachers must receive moral and psychological support. The implementation phase may be involved since teachers have to get used to new teaching methods and material, resulting in mental turmoil. Consequently, key institutions such as the education ministry must devise ways of promoting teachers' welfare. Professional support is also vital in achieving the long-term goals of a new curriculum. Teachers should undergo regular training to make the delivery process more effective. Given that most issues relating to curriculum change become evident during the implementation phase, teachers should always receive regular training that addresses all the shortcomings. When teachers feel supported by local and national agencies, they become confident that the changes will lead to better societies and work hard towards attaining the curriculum goals (McNeill, Katsh-Singer, González-Howard \& Loper, 2016). Therefore, administrative and professional support is essential in making curriculum changes a success.

\subsection{Administrative Influence}

Institutional leadership is also vital in determining whether educators will successfully implement desired changes. The management should support the changes to impact the teachers in achieving the developers' goals positively. When 
administrators have a negative attitude towards a change process, the junior staff develops a similar character making it hard to achieve the desired results. The administrators need to be trained on managing change to understand their role in creating a winning environment among teachers and learners (Torres, 2016). Trust building and mutual respect are vital in attaining high success levels. The learning environment becomes conducive when teachers believe in the internal and external systems to achieve the set targets. Administrators should also guide the reporting process where educators meet with the management to assess the progress and alternative courses of action (MacDonald, Barton, Baguley Hartwig, 2016). Consequently, administrators should be well informed on managing change to make the implementation process successful.

\section{Conclusion}

An effective curriculum should consider the needs of all stakeholders to ensure that every party understands its individual and collective duties towards the attainment of high success levels. A critical understanding of changes and innovation's social, economic, and political environment is vital in the implementation phase. Curriculum 4.0 desires to cause a shift from the industrial to knowledge era through experimentation and exploration. The learners will adopt a liberal mindset to acquire various subjects and in-depth knowledge in a specific field. Given that technology is the core focus of global societies, learners will get an opportunity to understand all emerging market trends.

Theoretical analysis of curriculum changes and innovation is vital in defining the educational concerns and devising effective implementation strategies. The complexity theory advocates the need to change depending on the external environment. When one system changes, such as the information technology industry, there is a need to implement changes in other interlinked fields to foster high growth levels. Technological development has resulted in changing workplace environments necessitating the need for the educational sector to adopt new teaching guidelines that align learners with the current and future market needs. The critical theory facilitates an in-depth understanding of the prevailing needs and adopting change measures that improve productivity. The theory evaluates how best existing systems can be improved and the potential barriers and solutions. Through a critical understanding of the theories, implementers and developers can understand the need to implement effective curriculums.

Additionally, the change process entails adherence to guiding processes and procedures. The ORC model advocates for cohesion among stakeholders to ensure the resistance levels remain low. Some of the key concerns addressed by the model include unrelated, personal, task-related, and impact-related issues. The LOC model advocates for sound leadership in achieving the long-term goals of the curriculum. Individuals should be well informed of the changes through regular training and adequate learning materials. The RCA model also advocates for an organizational structure that promotes a positive learning environment. Teachers should focus on individual students' needs on learning design to ensure that all people understand the long-term goals. Some key issues include teachers' concerns, administrative and professional support, and administrative influence. Curriculum developers can achieve the long-term vision of the desired changes and innovations through continuous support.

\section{References}

Aarons, G. A., Ehrhart, M. G., Farahnak, L. R., \& Hurlburt, M. S. (2015). Leadership and organizational change for implementation (LOCI): a randomized mixed method pilot study of a leadership and organization development intervention for evidence-based practice implementation. Implementation Science, 10(1). https://doi.org/10.1186/s13012-014-0192-y

Alsubaie, M. A. (2016). Curriculum development: Teacher involvement in curriculum development. Journal of Education and Practice, 7(9), 106-107.

Bank, L., Jippes, M., Leppink, J., Scherpbier, A. J., den Rooyen, C., van Luijk, S. J., \& Scheele, F. (2017). Are they ready? Organizational readiness for change among clinical teaching teams. Advances in Medical Education and Practice, Volume 8, 807-815. https://doi.org/10.2147/amep.s146021

Bell, H. (2014). The Dead Butler revisited: grammatical accuracy and clarity in the English Primary Curriculum 20132014. Language and Education, 29(2), 140-152. https://doi.org/10.1080/09500782.2014.988717

Blackmore, P., \& Kandiko, C. (2012). Strategic curriculum change: Global trends in universities. Routledge/SRHE.

Cetin, N. I. (2016). Effects of a teacher professional development program on science teachers' views about using computers in teaching and learning. International journal of environmental and science education, 11(15), 8026-8039.

Deogratias, E. (2018). The possible ways of practicing complexity theory through concept study in mathematics class. International Journal Of Curriculum And Instruction, 10(2), 142-151.

Fenwick, T., \& Dahlgren, M. A. (2015). Towards socio-material approaches in simulation-based education: lessons from 
complexity theory. Medical Education, 49(4), 359-367. https://doi.org/10.1111/medu.12638

Fleming, T. (2016). Reclaiming the emancipatory potential of adult education: Honneth's critical theory and the struggle for recognition. European Journal For Research On The Education And Learning Of Adults, 7(1), 13-24.

Giroux, H. A. (2019). Beyond the limits of radical educational reform: Toward a critical theory of education. Journal of Curriculum Theorizing, 2(1).

Global Focus. (2021). Curriculum 4.0 for Industry 4.0. Global Focus. Retrieved 12 October 2021, from https://www.globalfocusmagazine.com/curriculum-4-0-for-industry-4-0/

Hiver, P., \& Dörnyei, Z. (2015). Language teacher immunity: A double-edged sword. Applied Linguistics, amv034. https://doi.org/10.1093/applin/amv034

Kandiko Howson, C., \& Kingsbury, M. (2021). Curriculum change as transformational learning. Teaching in Higher Education, 1-20. https://doi.org/10.1080/13562517.2021.1940923

Kershner, B., \& McQuillan, P. (2016). Complex adaptive schools: Educational leadership and school change. Complicity: An International Journal Of Complexity And Education, 13(1), 4-29.

Kolmos, A., Hadgraft, R. G., \& Holgaard, J. E. (2015). Response strategies for curriculum change in engineering. International Journal of Technology and Design Education, 26(3), 391-411. https://doi.org/10.1007/s10798-015-9319-y

MacDonald, A., Barton, G., Baguley, M., \& Hartwig, K. (2016). Teachers' Curriculum Stories: Perceptions and preparedness to enact change. Educational Philosophy and Theory, 48(13), 1336-1351. https://doi.org/10.1080/00131857.2016.1210496

Mahatma Gandhi National Council of Rural Education. (2020). Curriculum Design and Content Development. Faculty Development Centre, 18-21. Retrieved 12 October 2021, from http://www.mgncre.org/pdf/PMMMNMTT/Module\%2003\%20Curriculum\%20Design\%20and\%20Content\%20De velopment.pdf

Mahmood, T. (2018). What models of change can be used to implement change in postgraduate medical education? Advances in Medical Education and Practice, Volume 9, 175-178. https://doi.org/10.2147/amep.s160626

McArthur, J. (2021). The Inclusive University: A Critical Theory Perspective Using a Recognition-Based Approach. Social Inclusion, 9(3), 6-15. https://doi.org/https://doi.org/10.17645/si.v9i3.4122

McNeill, K. L., Katsh-Singer, R., González-Howard, M., \& Loper, S. (2016). Factors impacting teachers' argumentation instruction in their science classrooms. International Journal of Science Education, 38(12), 2026-2046. https://doi.org/10.1080/09500693.2016.1221547

Rakes, G. C., \& Dunn, K. E. (2015). Teaching online: Discovering teacher concerns. Journal of Research on Technology in Education, 47(4), 229-241. https://doi.org/10.1080/15391523.2015.1063346

Teressa, T. D., \& Besha, G. (2020). The role of university-industry linkage in implementing competency-based curricula in public higher learning institutions in Ethiopia: A review literature. Logistics \& Supply Chain Review, 1(1), 12-31.

Torres, A. C. (2016). The uncertainty of high expectations. Journal of School Leadership, 26(1), 61-91. https://doi.org/10.1177/105268461602600103

Tran, N. H., Hallinger, P., \& Truong, T. (2017). The heart of school improvement: a multi-site case study of leadership for teacher learning in Vietnam. School Leadership \& Management, 38(1), 80-101. https://doi.org/10.1080/13632434.2017.1371690

Wang, V. C. X., \& Torrisi-Steele, G. (2015). Online teaching, change, and critical theory. New Horizons in Adult Education and Human Resource Development, 27(3), 18-26. https://doi.org/10.1002/nha3.20108

\section{Copyrights}

Copyright for this article is retained by the author(s), with first publication rights granted to the journal.

This is an open-access article distributed under the terms and conditions of the Creative Commons Attribution license which permits unrestricted use, distribution, and reproduction in any medium, provided the original work is properly cited. 